\title{
Evaluation of Antimicrobial Activity of Biosynthesized Iron and Silver Nanoparticles Using the Fungi Fusarium Oxysporum and Actinomycetes sp. on Human Pathogens
}

Abdeen Sunitha ${ }^{1}$, R.S.Rimal Isaac ${ }^{1}$, Geo Sweetly ${ }^{2}$, S. Sornalekshmi ${ }^{2}$, Rose Arsula ${ }^{3}$, P.K. Praseetha ${ }^{1}$ *

${ }^{1}$ Department of Nanotechnology, Noorul Islam University, Kumaracoil, Tamil Nadu, India.

${ }^{2}$ Department of Microbiology, Noorul Islam College of Arts and Sciences, Tamil Nadu, India

3 Department of Nanotechnology, Udaya School of Engineering, Vellamodi, Tamil Nadu, India.

* Corresponding author: crkpkp@gmail.com

Tel/fax.: +919486855091

\section{Abstract}

A simple and reproducible biosynthetic method was employed to synthesize iron and silver nanoparticles which resulted in monodispersed nanoparticles of high concentration. The iron oxide nanoparticles has been widely favored because of low cytotoxicity, biodegradable and reactive surface that can be modified with biocompatible coatings. Silver nanoparticles have been a potent antibacterial, antifungal, anti-viral and antiinflammatory agent. The reaction process was simple, eco-friendly, inexpensive and easy to handle. Green and chemical methods were employed to synthesize iron and silver nanoparticles. A microbial route to synthesize iron and silver nanoparticles by the fungal strain Fusarium oxysporum sp. and Actinomycetes sp. was done simultaneously. Production of nanoparticles using fungi has some advantages over other organisms as it is easy to handle and require simple raw materials. The obtained iron and silver nanoparticles were characterized by UV-vis spectroscopy, Fourier transform infrared spectroscopy (FTIR) and the morphology of prepared nanoparticles was confirmed by Transmission electron microscopy (TEM). TEM images of Iron nanoparticles synthesized by Fusarium oxysporum sp. showed 20-40 nm sized particles. These particles exhibited maximum antibacterial activity against Bacillus, E. coli and Staphylococcus sps. TEM images of biosynthesized silver nanoparticles were of smaller size (10-20 nm). The microbially synthesized silver nanoparticles using Actinomycetes were found to be highly toxic against different human pathogens due to the smaller size and due to the presence of antibiotic components available on them. The mechanism of antimicrobial property of nanoparticle lies with the fact that the extremely small size means a large surface area relative to the volume, which effectively covers the microorganisms and reduce oxygen supply for respiration. It was found that silver nanoparticles synthesized by the microbial route have a greater antibacterial activity.

Keywords: Iron nanoparticles, silver nanoparticles, Phyllanthus emblica, Fusarium oxysporum sp., Actinomycetes sp., microbial synthesis

Citation: A. Sunitha, et al. EEvaluation of antimicrobial activity of biosynthesized iron and silver Nanoparticles using the fungi Fusarium oxysporum and Actinomycetes sp. on human pathogens. Nano Biomed. Eng. 2013, 5(1), 39-45.

DOI: $10.5101 /$ nbe.v5i1.p39-45.

\section{Introduction}

Magnetic iron nanoparticles, a class of nanostructured material possess amenable properties making them important in view of biological applications. Since the changes in the electronic structure occur in the nanometer region, will affect the physical and chemical properties of the material [1]. These special phy-chemical properties of iron nanoparticles are not possible with traditional lipid or polymer-based nanoparticles. It has been demonstrated that a magnetic field can increase the uptake of magnetic iron nanoparticles with bacterial biofilms. The preparation method of magnetic iron oxide nanoparticles is simple. Iron oxide nanoparticles have been successfully prepared in the forms of aqueous phase or organic phase. The surface modification of iron nanoparticles which is performed by coating desirable molecular materials on surfaces improves stability, prevent aggregation of nanoparticles, ensure nontoxic status in physiological conditions and enhance the targeting function [2].

The two modes through which the micro-organisms synthesize iron oxide nanoparticles are biologically induced and controlled mineralization mechanisms (BIM and BCM). BIM mode allows extracellular synthesis of the magnetite crystals in the culture solution as a by-product and magnetite crystals. BIM can be observed in the Fe(III) reducing bacterial species of Shewanella, Geobacter, Archaeoglobus fulgidus, Thermoanaerobacter, and sulphate reducing bacterial species of Desulfuromonas acetoxidans. In contrast, biologically controlled mineralization (BCM) process initiates 
the microorganism itself to control the synthesis. The magnetite crystals are formed intracellularly. BCM mode can be observed in the magnetotactic bacteria (MTB) like Magnetospirillum magnetotacticum [3], M. gryphiswaldense [4] and sulphate-reducing magnetic bacteria (Desulfovibrio magneticus) [5]. The use of plant extracts for synthesis of nanoparticles is advantageous as it contains biomolecules that can function as both reducing and capping agents, eliminating the use and generation of substances hazardous to human health and the environment. The nontoxic, renewable raw materials and environmentally benign solvents are generally considered in a green synthetic strategy. The most common methods to synthesize iron nanoparticles chemically are as follows: co-precipitation [6], thermal decomposition [7], hydrothermal synthesis [8], microemulsion [9], sonochemical synthesis [10]. In addition, these nanoparticles can also be prepared by the other methods such as electrochemical synthesis [11], laser pyrolysis techniques [12], microorganism or bacterial synthesis $[13,14]$. The unique combination of high magnetization and paramagnetic behavior opens these materials to a very wide range of applications. Greater availability of the surface area facilitates in biosensor [15], drug delivery [16] and tissue repair [17], MRI [18], hyperthermic effect [19], cell tagging and tracking [20], gene delivery [21,22], detection of probes [23,24], in agriculture, biosensor, rapid separation in environmental biology and concentration tracing of specific targets, such as bacteria, leukocyte and protein [25]. The metallic nanoparticles are most promising as they contain antibacterial properties due to their large ratio betwwen surface area and volume.

Among noble-metal nanomaterials, silver nanoparticles have received considerable attention due to their attractive physicochemical properties. The Surface Plasmon Resonance and large effective scattering cross section of individual silver nanoparticles make them ideal candidates for molecular labelling [26]. Ionic silver is highly toxic to most bacterial cells and has long been used as a potent bactericidal agent [27]. Biological synthesis of such nanomaterials has gained significant interest due to the use of mild experimental conditions of temperature, $\mathrm{pH}$ and pressure. The silver nanoparticles were first synthesized by the bacterium Pseudomonas stutzeri. Silver nanoparticles were synthesized with a size smaller than $200 \mathrm{~nm}$. The fungi (eg., Verticillium, Aspergillus flavus) and actinomycetes (Thermomonospora) being extremely good candidates for extracellular process and also environmental friendly. The Actinomycetes Thermomonospora $s p$., synthesized silver nanoparticles extracellularly. Some marine actinomycetes strain of Streptomyces glaucus synthesized silver nanoparticles extracellularly and the particles ranging from $4 \mathrm{~nm}$ to $25 \mathrm{~nm}$ [28-32]. Silver nanoparticles being extensively synthesized using various plant leaf extracts such hibiscus (Hibiscus rosasinensis) leaf extract [33] neem (Azadirachta indica) leaf broth [34] of black tea leaf extracts [35] Indian gooseberry (Emblica officinalis) fruit extract [36] sundried camphor (Cinnamomum camphora) [37] and Aloe vera plant extract [38]. Chemical reduction is the most frequently applied method for the preparation of silver nanoparticles as stable, colloidal dispersions in water or organic solvents. Commonly used reductants are borohydride, citrate, ascorbate, and elemental hydrogen. The large scale synthesis of silver nanomaterial by chemical method suffers from issues such as polydispersity and stability, especially if the reduction is carried out in aqueous media. Therefore the extracellular biological synthesis of silver nanoparticles could be an attractive and ecologically friendly alternative method for the preparation of large quantities because it offers the advantage of easy downstream processing. Moreover, bacteria are easy to handle and can be manipulated genetically without much difficulty. Currently, there is a growing need to use environmentally friendly nanoparticles that do not produce toxic wastes in their synthesis protocol.

Biological methods using plant extracts and microorganisms have been proposed as an alternative environmentally friendly method in the synthesis of metallic nanoparticles. Biologically synthesized nanoparticles have special applications in health and medical fields since chemical synthesis methods leads to the presence of some toxic chemical species adsorbed on the surface of nanoparticles. The present work involves synthesis of iron and silver nanoparticles by three methods and further evaluating the antimicrobial activity of these biologically synthesized iron and silver nanoparticles.

\section{Material and methods}

\subsection{Microbial synthesis of iron and silver nano- particles}

\subsubsection{Synthesis of iron nanoparticles}

The fungal strain of Fusarium oxysporum used in this study was collected from the Kerala Agriculture University, Trivandrum. The fungal strains were morphologically and microscopically characterized and it was observed that all the strains were confirmed as Fusarium oxysporum. The fungal culture Fusarium oxysporum was collected and the mass culture of inoculum was produced. $20 \mathrm{~g}$ (wet weight) of $F$. oxysporum was then resuspended in $100 \mathrm{ml}$ aqueous solutions of $\mathrm{K}_{3} \mathrm{Fe}(\mathrm{CN})_{6}$ and $\mathrm{K}_{4} \mathrm{Fe}(\mathrm{CN})_{6}(\mathrm{pH} 3.1)$ ( $2: 1$ molar ratio) in $500 \mathrm{ml}$ Erlenmeyer flasks and kept on a shaker $(200 \mathrm{rpm})$ at $27{ }^{\circ} \mathrm{C}$. The reaction was carried out for a period of $120 \mathrm{~h}$. In a control all the experimental conditions were kept similar, except that $20 \mathrm{~g}$ of each fungal biomass was separately exposed to sterilized deionised water instead of iron complex. The biotransformed products were collected by separating the fungal mycelia from the aqueous extract by filtration under sterile conditions. 


\subsubsection{Synthesis of silver nanoparticles}

The actinomycete strains were isolated from heavy metal polluted and non-polluted soil samples. The polluted samples were collected from Travancore Titanium Products Ltd, Thiruvananthapuram and nonpolluted sample was collected from Noorul Islam college of Arts and Science, Kumaracoil. The species identified in the non-polluted soil were Streptomyces $s p$. I, Streptomyces sp. II, Streptomyces sp. III, Rothia sp., Actinomadura sp. and Rhodococcus sp. In the heavy metal polluted soil sample four species were identified which were, Streptomyces sp. I, Streptomyces sp. II, Streptomyces sp. III and Rhodococcus sp. The results revealed that Streptomyces sp. was the predominant actinomycetes in both the soil samples. Screening of actinomycetes was performed using nitrate reduction test. For the production of biomass, the actinomycetes strains such as Streptomyces sp. I (P1), Rhodococcus sp. (P8) and Streptomyces sp. II (NP1) were grown aerobically in actinomycetes broth. $20 \mathrm{mg}$ of biomass (fresh weight) was grind well using mortar and pestle and mixed with $200 \mathrm{ml}$ of Millipore water in a $500 \mathrm{ml}$ Erlenmeyer flask and agitated in the same condition for $72 \mathrm{~h}$ at $37^{\circ} \mathrm{C}$. The same was repeated for the cell free filtrate (filtered water) along with experimental flask (20 ml filtered water in 200 $\mathrm{ml}$ of Millipore water). Biomass and water samples were randomly named as $\mathrm{B}$ and $\mathrm{W}$. The biomass strains were named as BP1, BP8 and BNP1. The filtered water samples were named as WP1, WP8 and WNP1. For the synthesis of silver nanoparticles, $50 \mathrm{ml}$ of $1 \mathrm{mM} \mathrm{AgNO}_{3}$ was mixed with $50 \mathrm{ml}$ of cell filtrate in a $250 \mathrm{ml}$ Erlenmeyer flask and agitated at $37{ }^{\circ} \mathrm{C}$ in darker condition. The same was done for the cell free filtrate $\left(50 \mathrm{ml}\right.$ of $1 \mathrm{mM} \mathrm{AgNO}_{3}$ with $50 \mathrm{ml}$ filtered water). Simultaneously, control without $\mathrm{Ag}^{+}$ was also run along with the experimental flasks. Color change was noted at specific intervals (12 h and $72 \mathrm{~h}$ ).

\subsection{Green synthesis of iron and silver nano- particles}

\subsubsection{Synthesis of iron nanoparticles using Phyllanthus emblica}

About $8 \mathrm{ml}$ of $0.1 \mathrm{M} \mathrm{FeCl}_{3}$ and $2 \mathrm{ml}$ of $0.2 \mathrm{M} \mathrm{FeCl}_{2}$ was added in a $100 \mathrm{ml}$ beaker. Subsequently, $10 \mathrm{ml}$ of Phyllanthus emblica (Indian gooseberry) extract was added drop by drop. A brown precipitate was formed initially. The reaction continued for 20 minutes before the beaker was removed from the magnetic stirrer. The $\mathrm{PH}$ was adjusted to 8 . After synthesis, the black precipitate formed was washed 3-4 times with distilled water to avoid errors due to high optical density of the solution. The nanoparticles were removed from the solution by magnetic separation. The experiment was done in duplicates to produce reproducibility.

\subsubsection{Synthesis of silver nanoparticles using Zingiber officinale (Ginger)}

Green synthesis of silver nanoparticles was carried out by using Ginger rhizome (Zingiber officinale). The extract was prepared by taking $10 \mathrm{gm}$, thoroughly washed ginger rhizome, taking upper part of the knife, chopped into the fine pieces and converting it into the paste using mortar-pestle followed by addition of $40 \mathrm{ml}$ of Millipore water, boiling for $2 \mathrm{~min}$ then filtered. The filtrate was centrifuged at $5000 \mathrm{rpm}$ for $15 \mathrm{~min}$ and collected the suspension, which was further used as ginger rhizome broth for the experiment. For reduction of $\mathrm{Ag}^{+}$ions $5 \mathrm{ml}$ of ginger rhizome broth was added to $50 \mathrm{ml}$ of $1.0 \times 10^{-3}$ $\mathrm{M} \mathrm{AgNO}_{3}$ separately at room temperature. The reaction mixture was stirred vigorously on a magnetic stirrer plate. The solution turned light yellow and a brighter yellow.

\subsection{Chemical synthesis of iron and silver nano- particles}

\subsubsection{Synthesis of iron nanoparticles}

Iron nanoparticles were chemically synthesized using $8 \mathrm{ml}$ of $0.1 \mathrm{M}$ of $\mathrm{FeCl}_{3}$ and $2 \mathrm{ml}$ of $0.2 \mathrm{M} \mathrm{FeCl}_{2}$ solutions under ambient conditions. $50 \mathrm{ml} \mathrm{NaOH}$ was added drop by drop, a brown colored precipitate was formed initially with ferrous and ferric hydroxide dehydrates giving brownish precipitates. These iron nanoparticles showed attractive property when a strong magnet was moved along the test tube indicating the presence of iron nanoparticles.

\subsubsection{Synthesis of silver nanoparticles}

A large excess of $\mathrm{NaBH}_{4}$ was needed to reduce the ionic silver and to stabilize the silver nanoparticles formed. 10 $\mathrm{ml}$ volume of $1.0 \mathrm{mM} \mathrm{AgNO}_{3}$ was added drop wise (about one drop/sec) to $30 \mathrm{ml}$ of $2.0 \mathrm{mM} \mathrm{NaBH}_{4}$. The reaction mixture was stirred vigorously on a magnetic stirrer plate. The solution turned light yellow after the addition of 2 $\mathrm{ml}$ of $\mathrm{AgNO}_{3}$ and brighter yellow when all of the $\mathrm{AgNO}_{3}$ had been added. After which the stirring was stopped and the stirrer bar was removed. The presence of silver nanoparticles can be identified by color change.

\section{Characterization of iron and silver nano- particles}

\subsection{UV-vis spectroscopy of iron and silver nano- particles}

Iron and silver nanoparticles synthesized by all the three methods were analyzed for UV-Vis spectroscopy. The UV-Vis spectroscopy measurements of iron and silver nanoparticles were recorded on Systronic double beam spectrophotometer: 2202. Microbially synthesized iron and silver nanoparticles were measured in a wavelength of 200-1100 $\mathrm{nm}$ and $420 \mathrm{~nm}$ respectively. The progress of the reaction between metal ions and the gooseberry extracts were monitored by UV-Vis spectra of iron nanoparticles. UV-Vis spectroscopy analyses of chemically synthesized iron nanoparticles measured at $288 \mathrm{~nm}$. Green and chemically synthesized silver nanoparticles were measured in a wavelength ranging from 200-1100 nm. 


\subsection{Transmission Electron Microscopy (TEM) of iron and silver nanoparticles}

The prepared iron and silver nanoparticles were analyzed using TEM. The iron and silver nanoparticles were taken for TEM analysis on carbon-coated copper TEM grids. The films on the TEM grids were allowed to stand for 2 min following which the extra solution was removed using a blotting paper and the grid was allowed to dry prior to measurement.

\subsection{Antibacterial activity}

The antimicrobial activity of iron nanoparticle was determined by agar well diffusion method. The antimicrobial activity are carried out for chemical, green and microbially synthesized iron nanoparticles using Bacillus sps., Pseudomonas sps., Vibrio sps., Staphylococcus sps., Streptococcus sps., E. coli sps., Klebsiella sps. and Proteus sps. The identified actinomycetes were tested for their antibacterial activity by disc diffusion method against pathogenic organisms like Staphylococcus aureus, Klebsiella pneumoniae, Proteus vulgaris, Pseudomonas aeruginosa and Escherichia coli.

\section{Results}

The Erlenmeyer flasks with the $F$. oxysporum biomass were a pale yellow color before the addition of iron nanoparticles and this change to a brownish color on completion of the reaction with $\mathrm{Fe}^{3+}$ for $28 \mathrm{~h}$.
The appearance of a yellowish-brown color in solution containing the biomass was a indication of the formation of iron nanoparticles in the reaction mixture [39]. In the initial period of 24 hour of treatment; no visible change in the colour of the solution was visible. Change in absorbance value (at $265 \mathrm{~nm}$ wavelength) of the solution during this period is thought to be due to secretion of protein/enzymes by the fungus. UV-Vis spectrum of microbially synthesized iron nanoparticles were measured in a wavelength ranging from 200-1100 $\mathrm{nm}$. Iron nanoparticles mainly show peaks at $286 \mathrm{~nm}$ (Fig. 1). Microbially synthesized silver nanoparticles are found to have characteristic absorption peak at 420

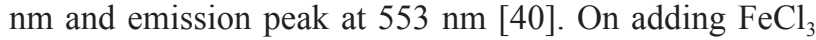
solution to the Phyllanthus emblica extract, the solutions instantaneously turned from pale yellow to dark brownish, indicating the formation of iron nanoparticles. The UV-

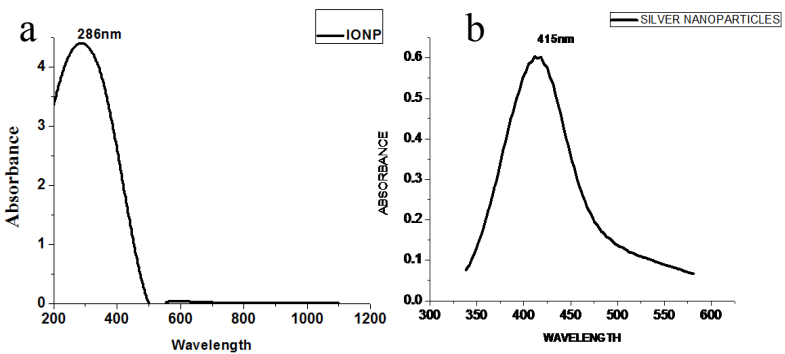

Fig. 1 UV absorption spectroscopy of microbially synthesized iron and silver nanoparticles.

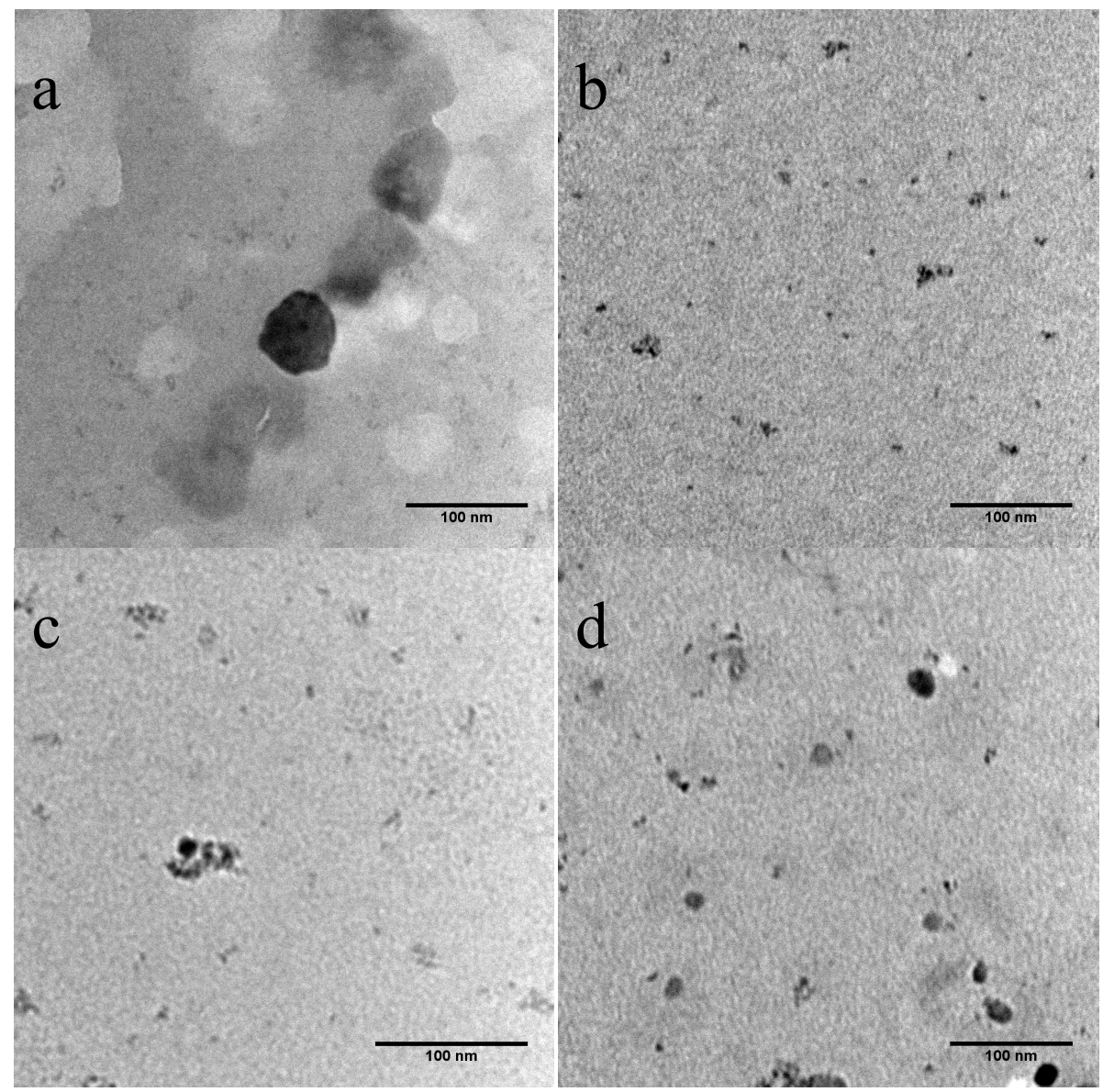

Fig. 2 TEM of nanoparticles at a magnification of 40,000. (a): green iron, (b): microbial iron, (c): chemical iron, (d): microbial silver 
Vis spectra of green synthesized iron nanoparticles were observed at $300 \mathrm{~nm}$. The UV-Vis spectrum of chemically synthesized iron and silver nanoparticles showed absorption peak at $286 \mathrm{~nm}$ and $415 \mathrm{~nm}$ indicating the formation of iron and silver nanoparticles.

TEM was used to determine the morphology and shape of nanoparticles. Low magnification TEM micrographs revealed that the particles are spherical in shape and uniformly distributed (monodispersed) without significant agglomeration. TEM results revealed that the iron nanoparticles synthesized using Indian gooseberry extracts were spherical with sizes ranging from 40 to 63 nm (Fig. 2a). The average size of microbially synthesized iron nanoparticles particles using TEM were $5.8 \mathrm{~nm}$ (Fig. 2b). TEM image of chemically synthesized iron nanoparticles are shown in Fig. 2c. The spheres have diameters of around $23 \mathrm{~nm}$. The particle size of microbially synthesized silver nanoparticles shows that the particle size is much smaller $(20 \mathrm{~nm})$ in Fig. $2 \mathrm{~d}$. The size of the nanoparticles were measured with the software.

The microbially synthesized iron nanoparticles prepared by the fungal strain showed antimicrobial activity against only Bacillus, E. coli, Staphylococcus sps. The antimicrobial activity can be identified by zone formation. The green synthesized iron nano particles prepared by Phyllanthus emblica showed activity against Klebsiella sps. The chemically synthesized iron nanoparticles prepared by co-precipitation method showed antimicrobial activity against only Streptococcus sps. The antibacterial activity of silver nanoparticles was investigated against various pathogenic bacteria of Gram-positive (Staphylococcus aureus) and Gramnegative (Escherichia coli, Pseudomonas aeruginosa, Klebsiella pneumoniae and Proteus vulgaris) strains using disc diffusion method. Control was also maintained

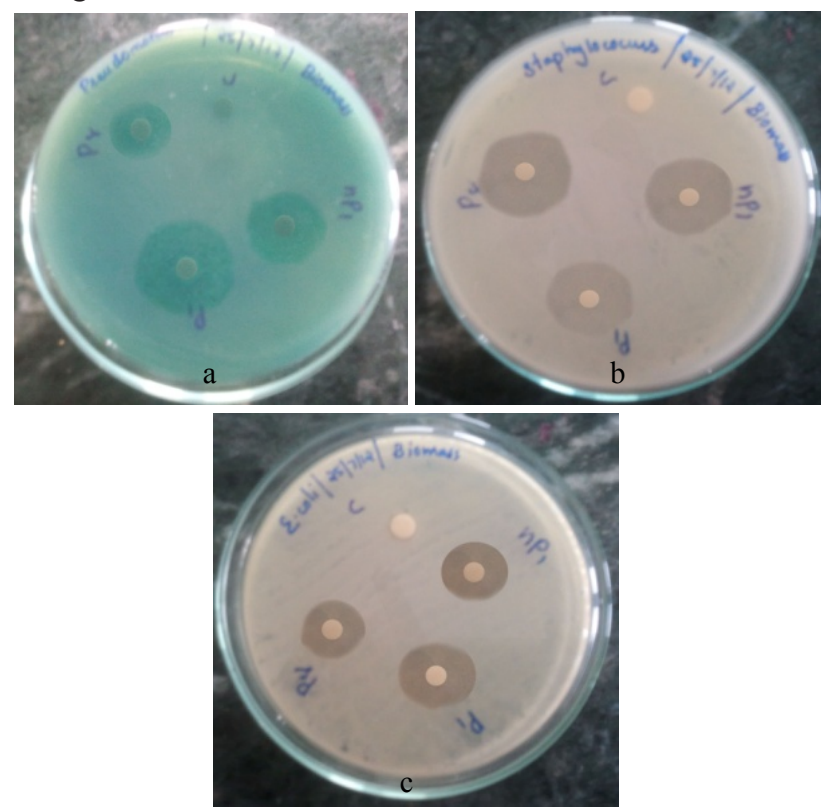

Fig. 3 Antibacterial activity of iron and silver nanoparticles against human pathogens with the largest zones. (a) Pseudomonas, (b) Staphylococcus, (c) E. coli. in which no zone of inhibition was observed. The highest antimicrobial activity was observed against Pseudomonas aeruginosa followed by Staphylococcus aureus and Klebsiella pneumoniae and the least was noticed against Proteus vulgaris and Escherichia coli. Some of the experimental samples with greater inhibition zones are represented in Fig. 3.

\section{Discussion}

The present research work has emphasized on biogenic synthesis of iron and silver nanoparticles using Fusarium oxysporum and actinomycetes $s p$. and antibacterial activity of synthesized nanoparticles with various pathogenic bacterial strains. The mechanism involved in the formation of metallic nanoparticles using biological systems is the bioreduction of ionic strength from their native ionic strength. The reduction in ionic concentration leads to the formation of size controlled and stable nanoparticles. The primary conformity of bioreduction of metallic ions is indicated by the change in their native colour. Many microorganisms including fungi are known to degrade cyanide and metal cyanide complexes. Fungi hydrolyze metal cyanide complex by the action of enzymes like cyanide hydratase or nitrilase, hydrolyses metal cyanide bond, releasing the free metal moiety. It is also well known that fungi which like $F$. oxysporum synthesize low molecular weight $\mathrm{Fe}^{3+}$ chelating compound called as siderophores. The transport of iron particles may be due to the presence of Siderophores. Iron transport molecules like hydroxamates are mainly present in fungi. They bind the complex molecules and transport them inside of cells. The secretion of proteins into the $\mathrm{FeSO}_{4}$ solution by the test fungus that brings about change in the oxidation-reductions potential of the $\mathrm{FeSO}_{4}$ solution. This finally brings about oxidations of $\mathrm{FeSO}_{4}$ [41]. The shifts in peaks of nanoparticles may be due to media compositions or size of particles. Thus, iron nanoparticle synthesis was an extracellular protein mediated process. The $\mathrm{AgNO}_{3}$ reacts with supernatant culture and shows the change in colour. The colour formation was mainly due to the surface Plasmon resonance of deposited silver nanoparticles and silver nanoparticles exhibit striking colors due to excitation of surface plasmon vibrations in the particles [42]. On adding $\mathrm{FeCl}_{3}$ to the aqueous gooseberry extract the solutions instantaneously turned from pale yellow to dark brownish, indicating the formation of iron nanoparticles. The formation of iron nanoparticles with polyphenols took by complexation with iron salts, reduction of iron and capping with oxidized polyphenols. Biomolecules found in plants induce the reduction of $\mathrm{Fe}^{3+}$ from $\mathrm{FeCl}_{3}$ to iron nanoparticles. The process of reduction is extra cellular and fast leading to the development of easy biosynthesis of iron nanoparticles. The polyol components and the water-soluble heterocyclic components are largely accountable for the reduction of $\mathrm{Fe}^{3+}$ and the stabilization of the nanoparticles. Similar studies were reported on the green synthesis of iron nanoparticles by using green tea 
and characterized the synthesized nanoparticles by TEM, UV-Vis spectroscopy and FTIR [43]. Iron nanoparticles were chemically synthesized by $\mathrm{Fe}^{3+}$ reduction using $\mathrm{NaBH}_{4}$ as a reducing agent under atmospheric condition; Formation of black colour indicates the presence of iron nanoparticles of about $100 \mathrm{~nm}$. When $\mathrm{AgNO}_{3}$ was added to the ginger extract, the solution immediately turned from pale yellow to yellow-brownish, indicating the formation of silver nanoparticles. TEM results reveal the size of silver nanoparticles prepared smaller compared to the size of silver nanoparticles prepared by green and chemical method which may be due to the concentration of phenolic compounds is critical to the size and morphology of metallic nanoparticles. Antibacterial activity of microbial synthesized iron nanoparticles was confirmed against Bacillus, E.coli and Staphylococcus sps. Antimicrobial activity is seen in microbially synthesized iron nanoparticles is due to the fact that ROS such as superoxide radicals $\left(\mathrm{O}^{2-}\right)$, hydroxyl radicals $(-\mathrm{OH})$, hydrogen peroxide $\left(\mathrm{H}_{2} \mathrm{O}_{2}\right)$, and singlet oxygen $\left({ }^{1} \mathrm{O}_{2}\right)$, cause damage to proteins and DNA in bacteria by generating oxidative stress. This is the main mechanism by which antibacterial drugs and antibiotics work [44].

The antibacterial activity of silver nanoparticles was investigated against various human pathogenic organisms using well diffusion method. The inhibition zone formed in the screening test indicates the antibacterial activity against various human pathogens. The antimicrobial mechanism of biosynthesized silver nanoparticles may differ from species to species of bacteria and size of the particles. The synthesized silver nanoparticles were more effective against gram positive bacterial strain than the gram negative bacteria. Silver nanoparticles have antimicrobial effect on Staphylococcus aureus. The reason for different sensitivity between Gram-positive and Gramnegative bacteria could be explain to the morphological differences between these microorganisms [45]. Gram-negative bacteria have an outer polysaccharide membrane carrying the structural lipopolysaccharide components. This makes the cell wall impermeable to lipophilic solutes. The Gram-positive strains should more susceptible having only an outer peptidoglycan layer which is not an effective permeability barrier.

\section{Conclusion}

The synthesis of iron and silver nanoparticles by microbial reduction, green and chemical methods has been demonstrated. TEM images of microbially synthesized iron nanoparticles showed particle size of about 20-40 nm and highly crystalline spherical metallic silver nanoparticles of about 10-20 nm were obtained. Microbially synthesized iron nanoparticles showed antimicrobial activity against only Bacillus, E.coli, Staphylococcus sps., whereas microbially synthesized silver nanoparticles showed highest antimicrobial activity against Pseudomonas aeruginosa, Staphylococcus aureus, Klebsiella pneumoniae, Proteus vulgaris and Escherichia coli. The "biogenic" approach is further supported by the fact that the majority of the bacteria inhabit ambient conditions of varying temperature, $\mathrm{pH}$, and pressure. The particles generated by these processes have higher catalytic reactivity, greater specific surface area, and an improved contact between the enzyme and metal salt in question due to the bacterial carrier matrix.

The biosynthesized nanoparticles are loaded with antibacterial substances synthesized by the fungi. These biomolecules in addition to the antibacterial activity of nanoparticles do produce better cytotoxicity against the pathogens. These results suggest that Biosynthesized silver nanoparticles are highly antagonistic in nature and they showed high antibacterial activity because silver nanoparticles allowed them to easily interact with other particles and increased their antibacterial activity due to its small size compared to the chemical and green synthesis. The smaller silver nanoparticles showed stronger antibacterial activity compared to the iron nanoparticles. These silver nanoparticles were of high purity, making them potentially useful for biological applications.

\section{References}

1 Salata O., Applications of nanoparticles in biology and medicine. J .Nanobiotechnol. 2004. 2:3.

2 Kim S, Kim JH, Jeon O, Engineered polymers for advanced drug delivery. J. Eur J Pharm Biopharm. 2009. 71(3):420-430.

3 Blakemore R.P. Magnetotactic bacteria. Annu. Rev. Microbiol. 1983. 36: 217-238.

4 Frankel R.B, Papaefthymiou G.C, Blakemore R.P and O'Brien W. $\mathrm{Fe}_{3} \mathrm{O}_{4}$ Precipitation in Magnetotactic Bacteria. Biochim. Biophys. Acta. 1998.763: 147.

5 Mandal D, Bolander M.E, Mukhopadhyay D, Sarkar G and Mukherjee P. The use of microorganisms for the formation of metalnanoparticles and their application. Appl. Microbiol. Biotechnol. 2006. 69: 485-492.

6 Nadagouda, M.N., Hoag, G., Collins, J. Varma, R.S. Green synthesis of Au Crystal Growth and Design. J.Am. Chem. Soc. 2009.9: 4979-4983.

7 Shouheng Sun and Hao Zeng, Size-controlled synthesis of magnetite nanoparticles. J. Am. Chem. Soc. 2002.124 (28): 8204-8205

8 Jun W, Jingjun S, Qian S, Qianwang C, One-step hydrothermal process to prepare highly crystalline $\mathrm{Fe}_{3} \mathrm{O}_{4}$ nanoparticles with improved magnetic properties. Materials Research Bulletin. 2003. 38:1113-1118.

9 Tucek, J.; Zboril, R.; Petridis, D. Maghemite nanoparticles by view of Mossbauer spectroscopy. J. Nanosci. Nanotechnol. 2006.6: 926-947.

10 Kim S, Kim J.H, Jeon O, Engineered polymers for advanced drug delivery. J. Eur. J. Pharm Biopharm. 2009. 71(3):420-430.

11 Li Z.Q, Chen Z.M, Preparation characterization and application of nano magnetic polymer materials. J. Chem Ind Times. 2007. 21 (6): 57-60.

12 Zhao, Z.L., Bian, Z.Y., Chen, L.X, He, X.W., Wang Y.F., Synthesis and surface modifications of iron oxide magnetic nanoparticles and applications on separation and analysis. Progress in Chemistry. 2006.18: 1288-1297.

13 Dobson J. Magnetic nanoparticles for drug delivery. Drug Development Research.2006 67: 55-60.

14 Solanki,A., Kim, J.D., Lee K.B., Nanotechnology for regenerative medicine: nanomaterials for stem cell imaging. Nanomedicine. 2008. 3: 567-578.

15 Maruoka S. Biocompatibility of polyvinyl alcohol gel as a vitreous substitute. Curr. Eye Res. 2006. 31(7-8):599-606.

16 Gupta A.K, Recent advances on surface engineering of magnetic iron oxide nanoparticles and their biomedical applications. 
Nanomed. 2007. 2(1):23-39.

17 Tartaj, P., Morales, M.P., Veintemillas V.S., Gonzalez Carreño, T., Serna, CJ, The preparation of magnetic nanoparticles for applications in biomedicine. J Phys D: Appl Phys. 2003.36:182-R197

18 Sun,C., Lee,J.S. \& Zhang, M,. Magnetic nanoparticles in MR imaging and Drug delivery. Advanced Drug Delivery Reviews. 2008. 60:1252-1265.

19 Thiesen,B. \& Jordan,A. Clinical applications of magnetic nanoparticles for hyperthermia. International Journal of Hyperthermia. 2008. 24: 467-474.

20 Becker,C., Hodenius, M., Blendinger,G., Sechi,A., Hieronymus,T., Schulte, DM., Rode,T.S.\& Zenke, M. Uptake of magnetic nanoparticles into cells for cell tracking. Journal of Magnetism and Magnetic Materials. 2007. 311:234-237.

21 Dobson, J. Magnetic micro- and nano-particle-based targeting for drug and Gene delivery. Nanomedicine. 2006.1: 31-37.

22 Plank, C. 2009. Nanomedicine: Silence the target. Nature Nanotechnology. 4:544-545.

23 Lin, P.C., Tseng, M.C., Su, A.K., Chen, Y.J. \& Lin, C. Functionalized magnetic nanoparticles for small-molecule isolation, identification, and quantification. Analytical Chemistry. 2007.79:3401-3408.

24 Hassen,M.W., Chaix,C., Abdelghani,A., Bessueille, F., Leonard, D. \& Jaffrezic- Renault,N. An impedimetric DNA sensor based on functionalized magnetic nanoparticles for HIV and HBV detection. Sensors and Actuators B: Chemical. 2008. 134:755-760.

25 Singh R, Lillard J.W. Nanoparticle based targeted drug delivery. J. Exp.Mol Pathol. 2009. 86(3):215-223.

26 Schultz, S.; Smith, D. R.; Mock, J. J.; Schultz, D. A. Single-target molecule detection with nonbleaching multicolor optical immunolabels. Proceedings of the National Academy of Sciences of the United States of America FIELD. 2000. 97: 996-1001.

27 Fox C.L, Modak S.M. Mechanism of silver Sulfadiazine Action on burn wound infections. Antimicrobial Agents and Chemotherapy. 1974, 5:582-588.

28 Kreibig U. and M. Vollmer, In: U. Gonser, R.M. Osgood, M.B. Panish, H. Sakaki, Eds., Optical Properties of Metal Clusters, Springer, Berlin. 1995. 207-234.

29 Slawson, R.M., Van Dyke, M.I., Lee H., Trevors. JT, Germanium and silver resistance, accumulation, and toxicity in microorganisms. Plasmid. 1992. 27: 72

30 Shahverdi, A.R.; Minaeian, S.; Shahverdi, H.R.; Jamalifar, H.; Nohi. Biosynthesis of iron and silver nanoparticles at room temperature using aqueous sorghum bran extracts.A.Process. Biochem. Amsterdam, Neth. 2007. 42: 919-923.

31 Jha, A.K.; Prasad, K.;. A green low-cost biosynthesis of $\mathrm{Sb}_{2} \mathrm{O}_{3}$ nanoparticles. Biochem. Eng. J. 2009. 43: 303-306.

32 Bharde, A.A.; Parikh, RY.; Baidakova, M.; Jouen, S.; Hannoyer, B.; Enoki, T.; Prasad, B.L.V.; Shouche, Y. S.; Ogale, S. Sastry, M. Bacteria-mediated precursor-dependent biosynthesis of superparamagnetic iron oxide and iron sulfide nanoparticles. Langmuir. 2008. 24: 5787-5794.
33 Philip, D., Green synthesis of gold and silver nanoparticles using Hibiscus rosasinensis. Physica E: Low Dimens. Syst. Nanostruct. 2010. 42: 1417-1424.

34 Shankar, S.S.; Rai, A.; Ahmad, A.; Sastry, M.J. Rapid synthesis of $\mathrm{Au}, \mathrm{Ag}$ and bimetallic Au shell nanoparticles using neem. Colloid Interface Sci. 2004. 275:496-502.

35 Begum, N.A.; Mondal, S.; Basu, S.; Laskar, R.A.; Mandal, D. Biogenic synthesis of $\mathrm{Au}$ and $\mathrm{Ag}$ nanoparticles using aqueous solution of black tea leaf extracts .Colloids Surf. 2009.71:113- 118.

36 Ankamwar, B.; Damle, C.; Ahmad, A.; Sastry, M.J., Biosynthesis of gold and silver nanoparticles using Emblica Officinalis fruit extract, their phase transfer and transmetallation in an organic solution. Nanosci. Nanotechnol. 2005. 1665-1671.

37 Huang, J.; Li, Q.; Sun, D.; Lu, Y.; Su, Y.; Yang, X.; Wang, H.; Wang, Y.; Shao, W.; He, N.; Hong, J.; Chen, C. Biosynthesis of silver and gold nanoparticles by novel sundried Cinnamomum camphora leaf. Nanotechnology. 2007.18:105104-105115.

38 Chandran, S.P.; Chaudhary, M.; Pasricha, R.; Ahmad, A.; Sastry, M. Synthesis of gold nanotriangles and silver nanoparticles using Aloe vera plant extract. Biotechnol. Prog. 2006. 22: 577-583.

39 Sastry, M., Patil, V., Sainkar, S.R. Electrostatically controlled diffusion of carboxylic acid derivatized silver colloidal particles in thermally evaporated fatty amine films. J. Phys. Chem. B. 1998.102: 1404.

40 Gurunathan, S., Kalishwaralal, K., Vaidyanathan, R., Venkataraman, D., Pandian S.R.K, Muniyandi, J., Hariharan N., and Eom S.H. Biosynthesis, purification and characterization of silver nanoparticles using Escherichia coli. Colloids Surf., 2009.74; 328- 335.

41 Durán, N., Priscyla M, Oswaldo, A.L., Gabriel, H.I. De. S, Elisa E. A Study on Biosynthesis of iron nanoparticle by pleurotus sp. Journal of Nanobiotechnology. 2005. 3:8

42 Kapoor, S; Preparation ,characterization and surface modification of silver particles. Langmuir. 1998.14:1021-1025.

43 Nadagouda, M.N.; Castle, A.B.; Murdock, R.C.; Hussain, S.M.; Varma, R.S. In vitro biocompatibility of nanoscale zerovalent iron particles (NZVI) synthesized using tea polyphenols. Green Chem. 2010. 12: 114-122.

44 Mahendra R., Alka Y., Aniket G. Silver nanoparticles as a new generation of antimicrobials. Biotechnol. Adv. 2009. 27: 76-83.

45 Ramgopal.M, Sai sushma, Attitalla I.H and Alhasin. A.M., A facile green synthesis of silver nanoparticles using soap nuts. Res.J.Microbiol. 2011. 6:432-438.

Copyright:(c) 2013 A. Sunitha, et al. This is an open-access article distributed under the terms of the Creative Commons Attribution License, which permits unrestricted use, distribution, and reproduction in any medium, provided the original author and source are credited. 